IJBE: Integrated Journal of Business and Economics

e-ISSN: 2549-3280

\title{
Political and Religious Contributions in Economic Development
}

\author{
Lia Kian \\ Asia Banking Finance and Informatic Institute (ABFII) Perbanas Jakarta \\ lia.kian@perbanas.id
}

\begin{abstract}
The great conclusion of this paper is to prove the synergy between religion and politics in the economic development of a State. The more polarized the system of ethical religious and political beliefs, the more help the economic development of a State. Based on the discourse on the religion and politics of the author in the direction of Beng-Lan Goh (2006), Wilson Erin K (2014), and Melleuish Gregory (2014) explaining the ideology of the state as an alternative logic forming religious symbolism from capitalist exploitation or commoditization, the best civilian politics in serving the people's welfare by rejecting the dichotomy of morality and interest systems, as well as religious and political understanding limits the capacity of religious clerics and actors in their significant influence on religious actions and rituals to the political sphere that greatly affects economic growth. The authors oppose the opinions of Bin Hassan (2007), San Juan (2011), Martinelli (2013) and Faux Jeff (2004) explaining that Effects of Islamic revival around the world in the competition of political power that directly and indirectly contribute to the development of Islam in politics, the United States and transnational geopolitical interests as a consequence of the contradiction between emerging and conservative nationalist impulses, the United States Congress that has successfully influenced key decisions on regulatory policy, has so far weakened existing systems and American economic politics flourish across borders, the same that happens in today's globalized economy. The data used in this paper comes from secondary data obtained from books, magazines, the Internet and other documentation relating to the study of the problems and this paper. This writing is descriptive qualitative with approach of research library.
\end{abstract}

Keywords: Politics, Religion and Growth of State Economy

\section{Pendahuluan}

Agama dan Negara merupakan dua variabel penting yang memiliki hubungan dengan pembangunan politik dan ekonomi suatu Negara. Agama dan Negara mengatur semua sisi kehidupan masyakat. Agama merupakan bingkai kepercayaan terhadap Tuhan yang maha esa dalam membangun karakter dan kepribadian manusia. Negara merupakan tempat tinggal manusia hidup dimuka bumi. Negara lahir sebagai syarat lahirnya suatu pemerintahan, melalui kedaulatan politik, maka Negara dan pemerintahan dapat diakui dan sejalan dengan sinergistas dengan pengakuan Agama sebagai kepercayaan ketuhanan masyarakat yang diakui oleh negara. Emile Durkheim mengatakan "ide tentang agama adalah roh masyarakat, (Pals, 2001). Beberapa kalangan berpendapat, Islam merupakan Agama satu kesatuan yang mempunyai kesatuan sosial politik yang tidak dapat dipisahkan, pendapat ini dipertegas oleh Abd Salam Sarif, dengan adanya doktrin "sesungguhnya islam itu adalah agama dan negara (Inna al-islaam Din Wa Daula)" (Abegriel, dkk, 2004). 
Menurut Azyumardi Azra islam bersifat ilahiah berasal dari wahyu sakral dan suci sedangkan politik berkenaan dengan kehidupan profan yang terkadang melibatkan trik-trik manupulatif, (Azra, 2000). Bahtiar Efendy juga menjelaskan bahwa islam politik telah menemukan format baru yang mencakup landasan teologis, di Indonesia prakteknya secara sintetis dapat dikembangkan antara pemikiran politik islam dan negara, (Efendy, 2001). Besarnya negara yang ada dalam islam, Nabi meninggalkan Madinah yang kemudian kepimpinannya diteruskan oleh Umar Bin Khatab, dimasa Umar Bin Khatab, Islam adalah bagian imperium dunia dari pantai timur atlantik hingga sampai pada Asia Tenggara, Menurut Abdrurahman Wahid ketidakjelasan konsep, yang menjadi konseptual negara islam berukuran mendunia atau sebuah bangsa saja, dan juga tidak jelas negara bangsa (nation state) ataukah negara kota (city state), (Wahid, 2006).

Konsep negara kota dalam pemikiran kenegaraan dari al-farabi yang dituangkan dalam karyanya Ara Alh al-Madinah al-Fadhilah merupakan konsep ini secara subtansial di ilhami atau di inspirasi atas karya plato dalam buku Republic, sehingga konsep al-Madinah al-Fadhilah, alfarabi berpendapat bahwa manusia adalah makluk sosial yang memiliki kebutuhan dalam hidup bermasyarakat atau bernegara yang juga membutuhkan dalam memenuhi tujuan hidup kebahagian dunia dan akhirat. al-Farabi memberi warna islam islam dalam pada pandangan plato dan aristoteles adalah tujuan masyarakat ukhrawi dari pembentukan negara, (Soehina, 1996).

Menurut Richard Walzer (1985), idealisasi negara al-Farabi memandang tidak memandang realitas politik saat itu, dimana pemerintah islam berbentuk negara nasional, bagi al-Farabi sistem yang terbaik terdapat pada negara kota. Sedangkan menurut Suharto (2007), Islam adalah agama yang menjunjung tinggi peradaban dan harkat martabat kemanusiaan yang memadukan antara aspek material dan spiritual, keduniawian dan keukhrowian. Islam bertujuan menciptakan sebuah sistem dimana prinsip keadilan berada di atas keuntungan segelintir atau sekelompok orang.

Islam adalah agama yang menjunjung tinggi peradaban dan harkat martabat kemanusiaan. Islam selalu menjunjung tinggi prinsip keadilan dan kemaslahatan. Islam merupakan bagian integral pemikiran gerak dalam pembangunan dalam diri manusia. Islam peradaban menentang sistem modernitas yang lebih cenderung kapitalis dan mengekploitasi sumberdaya dengan mengabaikan prinsip kemaslahatan bangsa dan negara. Masyarakat muslim di negara islam hendaknya menjalakan syariat dan tabiat islam. Tabiat dan risalah Islam, menunjukkan bahwa Islam merupakan agama yang yang universial dan syari'at yang komprehensif, dimana syari'at Islam tabiatnya harus memasuki seluruh aspek kehidupan, sehinggga tidak terbayangkan urusan negara diabaikan dan diserahkan kepada kaum liberalis dan atheis. (Qardhawi, 2003).

\section{Diskursus Agama dan Politik}

Hubungan antara agama / religiusitas dan nilai-nilai demokrasi merupakan topik panas dalam ilmu politik. Di satu sisi, 'sekuler' memandang agama sebagai inheren yang bertentangan dengan sikap demokratis (karena dogmatisme dan tertutup pikiran) dan berpendapat bahwa religiusitas intens dapat menimbulkan hambatan bagi difusi nilai-nilai demokrasi. Di sisi lain, beberapa sarjana telah menantang keyakinan dan telah secara empiris menunjukkan bahwa agama tidak berarti dukungan yang lebih rendah untuk demokrasi. Menurut Filetti (2014) pengaruh religiusitas terhadap sikap politik menunjukkan bahwa agama dapat memainkan beragam peran dalam konteks yang berbeda tergantung pada bagaimana orang melihat itu dalam konseptualisasi yang lebih luas dari modernitas. Seperti yang terjadi di Georgia dan Azerbaijan. Menurut 
Laustsen (2013) studi tentang politik dan agama saat ini terfragmentasi ke tingkat yang hampir tidak dapat menyebutnya sebagai salah satu bidang akademik. Ada empat pendekatan yang berbeda secara fundamental untuk studi politik dan agama yang terdiri agama politik, politik agama, agama sipil dan teologi politik, empat pendekatan tersebut memilik hubungan antara politik dan agama dengan segala kompleksitasnya.

Di Indonesia hubungan agama dan politik telah didominasi menjadi salah satu birokratisasiperaturan isu agama kebijakan terhadap agama dari institusi pelaksana (yaitu, pengadilan atau birokrasi) dari modus delegasi (vertikal dibandingkan horizontal) yang membentuk hubungan antara pembuat kebijakan dan lembaga mengimplementasikannya. Sedangkan menurut Sezgin dkk, (2014) Heterogenitas agama memiliki dampak besar pada prospek pembangunan bangsa dan demokratisasi politik, dan pentingnya kebijakan terhadap agama, dalam proses demokrasi politik dalam suatu negara. Tradisi keagamaan termasuk penyiksaan dapat diartikan sebagai pelanggaran hak asasi manusia. Sama halnya dalam hal penyiksaan oleh masyarakat religius cenderung menjadi produk orientasi interpretatif. Berkaitan dengan agama, moral hak asasi manusia telah membuatnya menjadi sulit untuk mengakui bahwa agama bisa mentolerir tindakan kekerasan, (An-Na im, A. A., 2013).

Pemahaman agama dan politik membatasi kapasitas ulama dan aktor keagamaan sama-sama untuk merasakan pengaruh yang signifikan akan tindakan dan ritual keagamaan dalam ranah politik. Kegiatan didominasi agama, seperti shalat, zakat dan perhotelan untuk orang asing, dapat memiliki implikasi politik yang signifikan, baik dalam jangka pendek maupun jangka panjang hal demikian sebagai tindakan keagamaan mengambil makna politik, (Wilson, E. K., 2014). Hubungan antara agama sekuler di Australia sangat kompleks dan tidak ada transisi sederhana dari masyarakat agama yang sekuler. munculnya perintah moral dari perdebatan ekonomi dimulai pada paruh kedua abad kesembilan belas, di Australia di mana perdagangan bebas didasarkan pada teologi natural optimis berjuang dengan keyakinan yang memiliki akar kuat dalam bentuk sekuler Calvinisme, (Melleuish, G., 2014).

Black, Antony (2010) dalam studi nya menjelaskan bahwa Pemikir Muslim, dimulai dengan alMawardi (974-1058), berusaha untuk mengembalikan subsumption politik dalam agama, terutama selama revolusi Syiah abad keenam belas di Iran. Sementara hari ini, Barat memandang agama dan politik sebagai kategori yang terpisah, Muslim melihat ini akibat dari kegalan barat yang memisahkan agama dan politik. pemikiran politik Islam terutama didasarkan pada wahyu (ditafsirkan dalam berbagai cara), sementara pemikiran politik Barat didasarkan pada filosofi. Schall (1998) juga melihat pikiran dan keyakinan sekitarnya politik agama dari filsafat Aristoteles dimana filsafat dan agama posisinya yang lebih tinggi daripada politik.

Pengaruh agama dan politik dan sebaliknya tidak lagi menjadi sumber kontroversi akademis. Namun, kebanyakan ilmuwan politik dan sosiolog mengeksplorasi hubungan ini dengan berfokus pada suatu negara, di seluruh dunia dan di seluruh waktu untuk menjelajahi sifat dari hubungan antara agama dan politik. (Wilcox, C., 2004). Seperti komentar Haynes: "Gagasan sekularisasi dapat dipahami untuk menjadi baik anti-agama atau netral ke arah itu" istilah "sekularisme" membutuhkan definisi yang lebih luas. Untuk masyarakat multi-budaya dan multiagama, sekularisme bukan merupakan pilihan ideologis tapi strategi politik. (Kumaraswamy, P. $\mathrm{R}, 1996)$. 
Menurut Kramer, L. (2011) Teori politik Perancis Benjamin Constant (1767-1830), kekuasaan pemerintah atau kepemimpinannya dari pihak liberal yang muncul dalam Restorasi era politik Perancis, Rosenblatt menegaskan bahwa sejarah liberalisme Constant juga harus menekankan ide agamanya Protestan dan tanggapan untuk debat agama Eropa antara tahun 1780-an dan 1820-an. Begitu juga dengan pendapat dari Williams, R. (2001), agama di dunia dan memiliki pengaruh politik dan kehidupan publik hal ini menunjukan pentingnya keterlibatan agama dalam politik dunia, begitu juga menurut Niose, David. (2008:45-6) perlunya dibangun bagi kebebasan sipil dan kebebasan beragama.

Menurut Beng-Lan, G. (2006), dalam perspektif ekonomi hubungan antara politik negara dan dalam tindakan agama, tidak dapat dipisahkan antara sekuler dan sakral dalam konstitusi kehidupan masyarakat di Asia Tenggara dan membuat kontribusi penting dalam antropologi simbolik dengan penentuan kontradiksi dalam ideologi negara sebagai logika alternatif membentuk simbolisme agama dari eksploitasi kapitalis atau komoditisasi. Islam politik adalah fenomena modern, dengan akar dalam kondisi sosial politik dari negara-negara Muslim di abad kesembilan belas dan kedua puluh. Ini adalah produk dari interaksi masyarkat muslim, militer, politik, ekonomi, budaya, dan intelektual - dengan Barat selama dua ratus tahun terakhir, periode ketika kekuasaan Barat telah dalam kekuasaan dan Muslim telah menjadi objek, bukan subyek, dari sejarah, (Ayoob, M., 2004).

Pemimpin politik Muslim telah menegaskan prinsip dan tujuan demokrasi, good governance, kemakmuran ekonomi, keadilan sosial-ekonomi, hak asasi manusia dan pluralisme sebagai tujuan Islam tersebut. Dengan penetapan kebijakan mereka pada tujuan ini mereka juga telah menarik konstituen yang lebih luas yang mencakup Muslim dan non-Muslim, sekuler dan Islamis, dan telah mereda beberapa kekhawatiran pemerintah Barat telah dengan Islam dalam politik Islam, (Rane, H., 2011).

Teori politik merupakan suatu cara yang digunakan untuk memahami ilmu politik, dimana didalamnya terdapat penjelasan ilmu politik dan kaitannya dengan bagian-bagian ilmu politik lainnya. Menurut Thomas P. Jenkin dalam The Study of Political Theory, teori politik dibedakan dalam dua macam, yaitu:

1. Valuational, yang merupakan teori-teori yang mengandung nilai moral dan norma politik, dimana dalam teori ini segala sesuatunya harus mempertimbangkan baik buruk atau konsekuensinya. Yang termasuk teori valuational adalah filsafat politik, politik sistematis dan ideologi politik.

2. Non-Valuational, merupakan teori-teori yang membahas fakta-fakta politik tanpa mempersoalkan nilai moral maupun norma. Teori ini memberikan gambaran dan perbandingan fenomena politik dalam kehidupan nyata.

Di dalam teori politik terdapat konsep penentuan tujuan politik, bagaimana cara untuk mencapai tujuan itu dengan segala konsekuensinya. Teori-teori politik yang mempunyai dasar moral memiliki fungsi utama sebagai pedoman dalam mengatur hubungan-hubungan antara anggota masyarakat agar berjalan stabil dan dinamik. Ada tiga golongan yang termasuk dalam teori valuational, diantaranya adalah: 
1. Filsafat Politik, menjelaskan hubungan antara sifat dari alam semesta dengan sifat dari kehidupan politik, dimana dalam menyelesaikan persoalan politik menggunakan pandangan yang terpusat pada alam. Menurut filsuf Yunani, Plato, keadilan merupakan hakekat dari alam semesta yang sekaligus merupakan pedoman untuk mencapai kehidupan yang baik yang dicita-citakan olehnya.

2. Politik Sistematis, teori ini merealisasikan filsafat politik, menerapkan norma-norma dalam kegiatan politik.

3. Ideologi Politik

Ideologi merupakan suatu keyakinan atau ide yang muncul dalam pikiran seseorang berdasarkan pemikiran-pemikiran yang logis (masuk akal) yang kemudian menjadikan ide ini sebagai pedoman dalam kehidupannya sesuai dengan tujuan pemikirnya. Jadi ideologi politik merupakan suatu pedoman atau cara bertindak dalam pelaksanaan kekuasaan sesuai dengan tujuan awal.

Di bawah ini ada beberapa macam ideologi politik dunia, antara lain:

1. Liberalisme, suatu ideologi yang memberikan kebebasan individu tanpa batasan atau halangan dari pemerintah. Munculnya ideologi ini disebabkan karena ketatnya peraturan sehingga membuat kekuasaan bersifat otoriter, tanpa memberikan kebebasan berpikir kepada rakyatnya. Salah satu yang menganut ideologi liberalisme adalah Amerika.

2. Sosialisme, ideologi ini berbeda dengan liberalisme yang mengutamakan kepentingan individu, ideologi sosialisme lebih mengutamakan kebersamaan. Dalam sosialisme setiap individu harus berusaha untuk mendapatkan layanan yang layak untuk kebahagiaan bersama, misalnya pemerataan kesempatan kerja, pembagian hasil secara merata, bahan konsumsi secara menyeluruh dan lain sebagainya.

3. Demokrasi, yaitu kekuasaan ditangan rakyat. Pemerintah yang berasal dari rakyat, oleh rakyat dan untuk rakyat. Rakyat membuat ketetapan hukum bagi dirinya sendiri melalui dewan perwakilan yang kemudian dilaksanakan oleh pemerintah.

\section{Sinergisitas Agama dan Politik dalam Pembangunan Ekonomi}

Berdasarkan konstruk teori yang diperoleh dari diskursus terhadap agama dan politik dalam memberikan kontribusi pertumbuhan ekonomi suatu negara, dalam tulisan ini penulis searah dengan pendapat Beng-Lan, G. (2006), Wilson, E. K. (2014), dan Melleuish, G. (2014) yang menjelaskan ideologi negara sebagai logika alternatif membentuk simbolisme agama dari eksploitasi kapitalis atau komoditisasi, perlu nya membangun tatanan politik sipil yang terbaik yang bisa melayani kesejahteraan rakyat. Menolak dikotomi ketatnya moralitas dan sistem bunga dalam berusaha serta pemahaman agama dan politik membatasi kapasitas ulama dan aktor keagamaan yang memiliki pengaruh yang signifikan dalam tindakan dan keputusan keagamaan dalam ranah politik, seperti kegiatan perintah zakat dan munculnya perintah moral dalam moralitas ekonomi dan bisnis.

Pemerintah dalam negara memiliki andil besar dalam membangun tatanan politik sesuai dengan ajaran Agama. Sejarah politik islam dimana daerah Balkan misalnya merupakan salah satu pusat budaya dan seni pada Kekaisaran Ottoman, yang memberikan perhatian khusus dalam pengembangan wilayah ini dan membuat pusat pertumbuhan investasi ekonomi dan juga menjadi pusat politik dan budaya, (Özcan, N., 2013). Sejarah telah membuktikan bahwa politik dan agama meerupakan aspek penting dalam memajukan perekonomian suatu negara, dan sebalik nya bilang muncul sifat negatif dari dua aspek tersebut bisa membuat stagnan ekonomi suatu 
negara. Hal ini dijelaskan oleh Bin Hassan, M dalam studinya (2007) menjelaskan bahwa efek dari kebangkitan agama (Islam) di seluruh dunia dalam persaingan kekuasaan politik yang secara langsung dan tidak langsung memberikan kontribusi terhadap perkembangan Islam dalam politik. Periode awal Islam di daerah Malaysia, yang saat ini dikenal sebagai Malaysia Barat, berbeda dengan di Nusantara. Muslim telah tiba di Nusantara pada abad kelima akibat kegiatan perdagangan.

Menurut Jan Erik Lane dan Svante Ersson, (2002). Pembangunan dan pertumbuhan ekonomi juga dipengaruhi oleh Politik, dimana politik berpengaruh terhadap kebijakan ekonomi dan begitu juga sebaliknya bahwa ekonomi berpengaruh terhadap politik. Begitu juga dengan konsep ekonomi politik islam, menurut Masudul Alam Choudhury, Muhammad Syukri Salleh dan Abdad (1997), konsep ekonomi politik islam telah terdapat beberapa karya-karya yang telah dihasilkan melalui proses pengumpulan karya-karya ekonomi politik islam dengan melalui penelitian. Karya ekonomi politik islam seperti “Islamic Political Economy in CapitalistGlobalization”. Menurut Choudhury pengaplikasian ekonomi politik islam berkaitan dengan negara dan sub sistem pasarnya. Menurut Mohd Syakir Mohd Rosidi (2010) ekonomi politik islam sebenarnya berasal dari dua bidang yang utama yaitu bidang politik islam dan bidang ekonomi islam, begitu juga menurut Kosugi (2012) yang menyatakan bahwa ekonomi politik islam diantaranya tentang pembiayaan ekonomi, penjagaan alam sekitar, instituisi islam, perspektif global, sosio ekonomi dalam islam dan ekonomi islam.

Jan Erik Lane dan Svante Ersson juga mempertegas bahwa Politik sangat mempengaruhi pertumbuhan ekonomi dikarenakan faktor pertama kebijakan-kebijakan tertentu yang dilakukan oleh pemerintah dalam berbagai periode dapat memperbesar dan memperkecil pertumbuhan dan faktor kedua politik dapat membentuk iklim politik yang dapat mewarnai faktor-faktor penentu pertumbuhan ekonomi. Menurut Monzer Kahf, (2004), peta kekuatan baru dalam arena sosial politik mayoritas negeri islam, ada dua hal penting yakni pertama secara jangka pendek memperkuat jaringan untuk melebarkan pengaruh ekonomi politik gagasan ekonomi islam dan kedua adalah secara jangka panjang mendukung orientasi gerakan politik islam.

Selain itu juga, berbagai persoalan pentingnya merawat politik dan agama dalam sosial masyarakat untuk meningkatkan pertumbuhan ekonomi suatu kawasan atau suatu negara. Sebagai contoh yang dijelaskan oleh Irogbe, K. (2013), secara umum menjelaskan bahwa perusahaan multinasional telah secara politik telah mempengaruhi kedaulatan negara-negara berkembang, sebagai contoh perusahaan minyak internasional di Nigeria dan termasuk kebijakan luar negeri Amerika Serikat. Begitu juga halnya dengan promosi investasi langsung asing (Foreign Direct Investment) misalnya yang ada di Republik Ceko dan Slovakia, Ekonomi asing yang dipimpin di Eropa Tengah dan Timur pada akhir 1990-an dimana strategi ekonomi menuju model yang berbeda dari negara-negara pesaingnya, (Drahokoupil, J., 2008). Konsep hubungan material ekonomi yang juga ditentukan oleh politik, budaya, dan regulasi, hal demikian lebih bernuansa sebagai bentuk pola keagenan yang merupakan bagian dari identitas pasar, (Roscoe, P., 2013).

Kepentingan geopolitik Amerika Serikat dan transnasional sebagai bagian konsekuensi dari kontradiksi antara impuls nasionalis yang muncul dan konservatif yang juga terjadi di Filipina, (San Juan, E. 2011). Kongres Amerika Serikat yang berhasil mempengaruhi keputusan kunci 
mengenai kebijakan regulasi, sejauh ini telah melemahkan sistem yang ada terhadap kontrol kelembagaan dan untuk mencegah aturan baru untuk produk-produk keuangan baru, (Martinelli, A., 2013). Dimana hal demikian merupakan bagian dari dampak krisis ekonomi dan keuangan global dalam beberapa dekade terakhir ini Para analis politik telah menyatakan pentingnya pada budaya politik sekarang dalam memberi kontribusi untuk pertumbuhan ekonomi dan demokratisasi, (Rich, P. J., 1994). Politik ekonomi Amerika berkembang melintasi batas negara, proses yang sama yang terjadi dalam perekonomian yang mengglobal saat ini yang menegosiasikan perjanjian perdagangan dan investasi secara resmi mewakili kepentingan nasional yang berbeda, (Faux, J., 2004).

Konsep pemerintahan dan New Public Management (NPM) yang dilaksanakan 7th International Research Conference on Dilemmas for Human Services dimana masalah tata kelola pemerintahan telah menyebabkan hubungan yang lebih fleksibel antara pemerintah dan yang diperintah, (Radcliffe, J., dan Mike D., 2005). Kontroversi politik oleh pembiayaan publik di mana yang tujuannya masalah keadilan sosial yang berkaitan dengan distribusi pendapatan dengana tas dasar ini justifikasi untuk pendanaan publik, (Murray, D., 2009). Upaya restrukturisasi perkotaan bertujuan untuk membangun kembali lingkungan dalam kota yang umum di seluruh AS yang melibatkan koalisi aktor publik dan swasta yang memainkan peran komplementer dalam mempromosikan investasi, Organisasi nirlaba umumnya tidak dianggap sebagai pemain sentral dalam inisiatif ini, meskipun mereka sering melayani fungsi pembangunan masyarakat bagi penduduk yang tinggal di low income ruang miskin kota, (Fraser, J., 2014). Indikasi bahwa proyek-proyek yang diselenggarakan oleh pemerintah kota cenderung menunjukkan modal yang paling sosial, tidak ada hubungan antara jumlah pembiayaan proyek dan modal sosial, dan tingkat tinggi motivasi menyebabkan peningkatan modal sosial, (Teilmann, K., 2012).

Sebuah penelitian dilakukan investasi asing di Slovenia untuk mengeksplorasi interaksi arus investasi global, ketahanan terhadap kepemilikan asing, upaya proteksionis nasional, dan tekanan dari asosiasi regional. Temuan mengungkapkan bahwa pejabat negara Slovenia bernegosiasi dengan Uni Eropa dan tekanan domestik dengan mengesahkan decoupling praktek ekonomi dan politik formal. (Bandelj, N., 2004). Negara Islam seperti Maroko, Dalam beberapa tahun terakhir dimana kelompok-kelompok yang berkepentingan telah mengabaikan parlemen. Secara signifikan, media dan analis menghabiskan banyak waktu dalam pelacakan apa yang terjadi dalam dinding-dinding parlemen. Parlemen Maroko sebagai representasi politik dan hak pengawasan eksekutif yang akan berpengaruh terhadap pembuatan hukum bahkan berkaitan dengan meninjau dan menyetujui anggaran belanja. (Denoeux, G. P. dan Helen, R. D., 2007).

Kebijakan perkotaan di negara muslim seperti di Turki telah melakukan perubahan dengan melalui analisis antara neoliberalisme dan Islamisme. Dalam hal ini, yang jelas bukan proyek politik dengan tujuan akhirnya, melainkan kontekstasi antara neoliberalisme dan Islamisme didekati sebagai rasionalitas politik. Rasionalitas politik antara neoliberalisme dan Islamisme memilik perbedaan bertujuan dalam mengkonfigurasi semua aspek kehidupan sosial, (Karaman, O., 2013). Sejarah Islam dan demokrasi liberal. Sepanjang sejarah, dimana wilayah Muslim umumnya ditampilkan sangat sedikit fungsi demokrasinya, Namun demikian, unsur-unsur dalam hukum Islam yang dapat mendorong pengembangan beberapa bentuk demokrasi, Demokrasi biasanya berkembang dari gerakan menuju kebebasan. (Lewis, B., 1996). 
IJBE: Integrated Journal of Business and Economics

e-ISSN: 2549-3280

Populasi pendudukan dunia termasuk 1,620 juta orang yang merupakan bagian dari perluasan Ummat Islam, ditemukan dalam jumlah besar di seluruh wilayah dunia yang terkonsentrasi di Afrika, Asia, Timur Tengah. Beberapa negara Islam kebanyakan warga Muslim hidup dalam kondisi kemiskinan, pengangguran, buta huruf, sakit, kerusuhan sosial dan politik dan, di beberapa daerah, ekstremisme agama. (Estes, R., dan Habib T., 2014). Peran dan pengaruh negara pada operasi modal sosial dan politik sangatlah penting, sebagai contoh dapat dilihat melalui studi kasus perusahaan holding Islam di Turki dan jaringan sosial mereka dalam ruang transnasional. Dalam dua dekade terakhir, telah terjadi proliferasi perusahaan Islam, bank dan perusahaan holding yang dibentuk organisasi bisnis mereka sendiri pada tahun 1990.Pengeluaran modal perusahaan holding tersebut diciptakan, tanpa dasar hukum, melalui mobilisasi tabungan ratusan ribuan penabung kecil di Turki dan di seluruh Eropa. (Baki, A. E., 2009).

Negara islam seperti Suriah telah melakukan reformasi ekonomi dibawah kepemimpinan Presiden Bashar Assad yang telah mengeluarkan kebijakan reformasi ekonomi secara bertahap yang pada akhirnya menyebabkan peningkatan keterbukaan dalam pemerintahan otoriter Suriah. Suriah telah menarik investasi asing hanya terbatas dan pembangunan ekonomi. (Gifford, L. A., 2009). Mudrajad Kuncoro menjelaskan berbagai hasil studi menunjukkan bahwa iklim investasi Indonesia lebih buruk dibanding Cina,Thailand, Vietnam dan negara-negara ASEAN lainnya. Iklim investasi dapat didefinisikan 'sebagai semua kebijakan, kelembagaan, dan lingkungan, baik yang sedang berlangsung maupun yang diharapkan terjadi di masa mendatang, yang bisa mempengaruhi tingkat pengembalian dan risiko suatu investasi', investasi akan sangat dipengaruhi stabilitas politik. (Rajagukguk, E., 2007).

Dukungan ekonomi politik di Indonesia sangat diharapkan terutama yang berkaitan dengan investasi shariah dalam pembiayaan pembangunan perkotaan, sebagai buktinyata aspek ekonomi politik dapat memberikan kontribusinya dalam cita-cita pengembangan lembaga ekonomi islam. Pendirian lembaga ekonomi islam meredup disebabkan kurangnya dukungan politik. Pada tahun 1990-an menjelang jatuhnya Orde Baru titik awal menandai kelahiran ekonomi islam di Indonesia secara kelembagaan setelah dikeluakannya Undang-Undang No.7 tahun 1992 tentang perbankan secara implisit dimungkinkan penerapan bagi hasil. Kemudian peluang ini muncul dalam praktek perbankan tentang bagi hasil setelah dikeluarkannya Peraturan Pemerintah No.72 tahun 1992. (Wirdyaningsih, 2005). Sebagai contoh dari keterputusan antara norma-norma dan hasil Ekonomi politik moral yang menawarkan lensa yang inovatif untuk penilaian kritis hubungan Afrika, Karibia, dan Pasifik (ACP) dan Uni Eropa dimana Bank Investasi Eropa (EIB) dan kegiatan di negara-negara ACP fokus khusus pada Fasilitas Investasi Bank (IF). (Langan, M., 2014).

Proyek-proyek pembangunan dalam suatu wilayah tidak terlepas dari keputusan strategis dari para penguasa ditingkat level kepemimpnan nasional maupun daerah. Proyek-proyek pembangunan tersebut membutuhkan dana yang tidak sedikit yang dperlukan keseriusan oleh pemerintah maupun dari lembaga legelatif dalam melakukan sistem penganggaran yang teralokasi secara efektif. Efektifitas penggunaan dana-dana proyek-proyek pembangunan yang dipergunakan haruslah tepat guna dan tepat sasaran, dalam Sejarah perkembangan yang terjadi di negara-negara dunia hal demikian ini tidak pernah terjadi, dimana hal demikian dibuktikan hasil temuan winters yang menjelaskan bahwa proyek-proyek investasi yang didanai Bank Dunia 
menunjukkan hubungan negatif antara penargetan dan dan sasaran proyek investasi pembangunan. (Winters, M., 2014)

Begitu juga halnya dengan tren ke arah penyediaan layanan hukum hasil dari produk politik secara khusus yanga mengatur investasi didaerah terpencil atau setingkat pedesaan, yang memerlukan investasi yang lebih besar baik di tingkat struktural. (Franklin, A. dan Robert, G. L., 2007), dan begitu juga dengan saluran alternatif melalui lembaga mempengaruhi pertumbuhan, dan mempelajari hubungan empiris antara lembaga, investasi, dan pertumbuhan. (Dawson, J. W. 1998). Menurut Sri Edi Swasono Ketimpangan pembangunan wilayah antara desa dan kota, antara jawa dan luar jawa, antara pengusaha asing dan nasional harus direstruktur secara politik perlunya campur tangan pemerintah agar daulat pasar agar tidak menggusur daulat rakyat. Stabilitas politik negara tetap dijaga dan dipelihara karena menurut al-Mawardi stabilitas politik merupakan faktor penting dalam peningkatan hasil produksi dalam kemajuan ekonomi dan peluang investor asing dalam menanamkan modalnya, welfare state menurut al-Mawardi juga dilihat dari stabilitas nasional untuk memberikan rasa aman bagi investor, (Francis A., 1991).

\section{Kesimpulan}

Politik dan agama merupakan faktor penting dalam pembangunan nasional suatu bangsa begitu juga di Indonesia. Kedua variabel ini merupakan variabel eksternal dalam mempengaruhi kebijakan dan arah pembangunan ekonomi Negara Indonesia. Semakin baik kondisi politik dan keyakinan serta ketaatan dalam beragama maka akan semakin baik arah pembangunan ekonomi dalam menciptakan keadilan dan kesejahteraan masyarakat dan sebalik semakin tidak adanya sinergistas antara politik dan agama maka akan sulit bagi suatu Negara dalam melakukan pembangunan ekonominya.

Pentingnya dua variabel ini tetap menjadi fokus perhatian bagi semua komponen bangsa Indonesia tanpa terkecuali pemerintah akan tetapi masyarakat, pengusaha dan stakeholder lainnya bekerjasama dalam berafiliasi untuk menjalankan politik demokrasi yang baik dan terhormat yang selalu mengkedapan norma-norma dan aturan yang berlaku dengan dasar agama yang diyakini. Agama merupakan suatu keyakinan dengan aturan yang harus ditaati bagi pemeluknya, bagi agama islam Al-quran dan hadist merupakan pinjakan dan pedoman dalam membangun bangsa dan Negara. Afiliasi dan singergistas dari konteks politik dan agama akan memberikan kontribusi positif dalam pembangunan suatu bangsa, pinjakan politik dan keyakinan agama yang baik maka Indonesia akan maju dalam mengembangkan dan melaksanakan program pembangunan ekonomi jangka panjang yang berkeadilan yang didasari dasar Negara Pancasila yang juga mengatur tentang ketuhanan yang maha esa.

\section{Referensi}

Abraham, F. (1991). Perspective on Moderanization: Toward a General Theory of Third World Development, Rusli Karim, Modernisasi di Dunia Ketiga: Suatu Teori Umum Pembangunan. Yogyakarta: Tiara Wacana.

Alberto, M. (2013). Some Neglected Causes of the Global Financial Crisis and Their Implications for Effective Crisis Governance. Fudan Journal Of The Humanities \& Social Sciences, 6(3),103-136. 
IJBE: Integrated Journal of Business and Economics

e-ISSN: 2549-3280

An-Na im, A. A. (2013). Critical Reflections on Torture, Religion and Politics. Muslim World, 103(2), 259-266.

Ayoob, M. (2004). Political Islam: Image and Reality. World Policy Journal, (21)3, 1-14.

Azra, A. (2000). Islam subtantif: Agar Umat Tidak Jadi Buih. Bandung: Mizan.

Bandelj, N. (2004). Negotiating Global, Regional, and National Forces: Foreign Investment in Slovenia. East European Politics \& Societies (18)3, 455-480.

Beng-Lan, G. (2006). SPIRITED POLITICS: Religion and Public Life in Contemporary Southeast Asia. Pacific Affairs (79)2. http://search.proquest.com/docview/217699678?accountid=25704

Bin Hassan, M. (2007). Explaining Islam's Special Position and the Politic of Islam in Malaysia. Muslim World, (97)2, 287-316.

Black, A.. (2010). Religion and Politics in Western and Islamic Political Thought: A Clash of Epistemologies?. Political Quarterly, (81)1, 116-122.

Dale, M. (2009). Reflections on Public Funding for Professional Sports Facilities. Journal of the Philosophy of Sport, (36)1, 22-39.

Daniel, L. P. (2001). Dekontruksi kebenaran; Kritik Tujuh Teori Agama. Yogyakarta: IRCiSoD.

Dawson, J. W. (1998). Institutions, investment, and growth: new cross-country and panel data evidence. Economic Inquiry, (36)4, 603-619.

Denoeux, G. P., and Helen, R. D. (2007). Rethinking the Moroccan Parliament: The Kingdom's Legislative Development Imperative. Journal of North African Studies, (12)1, 79-108.

Drahokoupil, J. (2008). The Investment-Promotion Machines: The Politics of Foreign Direct Investment Promotion in Central and Eastern Europe. Europe-Asia Studies (60)2.

Edi, S. (2007). Kebijakan Sosial Sebagai Kebijakan Publik: Peran Pembangunan Kesejahteraan Sosial Dan Pekerjaan Sosial Dalam Mewujudkan Negara Kesejahteraan Indonesia. Bandung: Alfabeta

Efendy, B. (2001). Teologi Baru Politik Islam: Pertautan Agama, Negara dan Demokrasi. Yogyakarta: Galang Press.

Estes, R. and Habib, T. (2014). Development Trends in Islamic Societies: From Collective Wishes to Concerted Actions. Social Indicators Research, (116)1, 67-114.

Filetti, A. (2014). Religiosity in the South Caucasus: searching for an underlying logic of religion's impact on political attitudes. Journal Of Southeast European \& Black Sea Studies, (14)2, 219-238.

Franklin, A. and Robert, G. L. (2007). The Embedded Nature of Rural Legal Services: Sustaining Service Provision in Wales. Journal Of Law \& Society, (34)2, 218-243.

Gifford, L. A. (2009). Syria: The Change That Never Came. Current History (108)722, 417-423.

Irogbe, K. (2013). Global Political Economy and the Power of Multinational Corporations. Journal Of Third World Studies, (30)2, 223-247.

James, F. and Edward L. (2014). Governing urban restructuring with city-building nonprofits. Environment \& Planning A, (46)6, 1445-1461.

Jan, E. L. dan Svante, E. (2002). Ekonomi Politik Komparatif: Demokrasi dan Pertumbuhan Benarkah Kontradiktif. Jakarta: PT.RajaGrafindo Persada.

Jeff, F. (2004). Without Consent: Global Capital Mobility and Democracy. Economic Policy Institute: Winter, (51)1, 43-50. 
Kahf, M. (2004). Islamic Banking: The Rise of a New Power Alliance of Wealth of Islamic and Sharia Scholarship" dalam Henry M.Clement dan Rodney Wilson (Ed). Edinburgh: Edinburgh University Press and Colombia University Press.

Karaman, O. (2013). Urban Neoliberalism with Islamic Characteristics. Urban Studies (Sage Publications, (50)16, 3412-3427.

Kasper, T. (2012). Measuring social capital accumulation in rural development. Journal of Rural Studies, (28) $4,458-465$.

Kramer, L. (2011). Liberal Values: Benjamin Constant and the Politics of Religion. French Politics, Culture \& Society, (29)1.

Kumaraswamy, P. R. (1996). Religion in Third World Politics. Domes, (5)4. http://search.proquest. com/docview/205061070?accountid=25704.

Langan, M. (2014). A moral economy approach to Africa-EU ties: the case of the European Investment Bank. Review of International Studies, (40)3, 465-485.

Laustsen, C. B. (2013). Studying Politics and Religion: How to Distinguish Religious Politics, Civil Religion, Political Religion, and Political Theology. Journal of Religion in Europe (6)4, 428-463.

Lewis, B. (1996). Islam and liberal democracy: a historical overview. Journal of Democracy, (7), 52-63.

Masudul, A. C., Muhammad, S. S.dan Abdad. (1997). Islamic Political Economy in CapitalistGlobalization. Universiti Sains Malaysia: Publication and Distrutors Sdn.Bhd dan International Project on Islamic Political Economy (IPIPE).

Melleuish, G. (2014). A Secular Australia? Ideas, Politics and the Search for Moral Order in Nineteenth and Early Twentieth Century Australia. Journal of Religious History, (38)3, 398-412.

Mohd, S. M. R. (2010). Dr. Burhanuddin Al-Helmi dan Pembangunan Ekonomi Politik Islam di Malaysia. Universiti Sains Malaysia: Disertasi Non Publikasi.

Niose, David. 2008, "The Stillborn God: Religion, Politics, and the Modern West." The Humanist 68, no. 1: 45-6.

Özcan, N. (2013). Şuara Tezkirelerine Göre Selanikli Divan Şairleri. (Turkish)." Journal Of International Social Research, (6)26, 414-427.

Qardhawi, Y. (2003). Menuju Pemahaman Islam Yang Kaffah: Analisis Komprehensif Tentang Pilar, Karakteristik, Tujuan dan Sumber-Sumber Acuan Islam. Jakarta: Insan Cemerlang.

Rajagukguk, E. (2007). Hukum Investasi di Indonesia. Jakarta: Fakultas Hukum Universitas Al-Azhar Indonesia.

Rane, H. (2011). The Impact Of Maqasid Al-Shari'ah On Islamist Political Thought: Implications For Islam-West Relations. Islam and Civilisational Renewal, (2)2, 432-433.

Roscoe, P. (2013). Economic embeddedness and materiality in a financial market setting. Sociological Review, (61)1, 41-68.

San, J. E. (2011). Contemporary Global Capitalism and the Challenge of the Filipino Diaspora. Global Society: Journal Of Interdisciplinary International Relations, (25)1, 7-27.

A.Maftuh, A., dkk. (2004). Negara Tuhan: The Thematic Echlopedia. Yogyakarta: SR-Ins Publishing.

Schall, J. V. (1998). Aristotle: Religion, Politics, and Philosophy. Perspectives on Political Science, (27)1, 5-12. http://search.proquest.com/docview/194693743?accountid=25704. 
IJBE: Integrated Journal of Business and Economics e-ISSN: 2549-3280

Sezgin, Y. and Mirjam, K. (2014). Regulation of "Religion" and the "Religious": The Politics of Judicialization and Bureaucratization in India and Indonesia. Comparative Studies In Society \& History, (56)2, 448-478.

Soehina. (1996). Ilmu Negara. Yogyakarta: Liberti.

Wahid, A. (2006). Islamku Islam Anda Islam Kita: Agama Masyarakat Negara Demokrasi. Jakarta: Wahid Institut.

Walzer, R. (1985). al-farabi on The Perfect State: Abu Nasr al-Farabi's Mabadi Ara Ahl al-Madinah alFadilah. Newyork: Oxford University, Press.

Wilcox, C. (2004). Politics \& Religion. Political Science Quarterly, (119). http://search.proquest. com/docview/208280623 ?accountid=25704.

Williams, R. (2001). The Desecularization of the World: Resurgent Religion and World Politics. Sociology of Religion (62)1. http://search.proquest.com/docview/216768923?accountid $=25704$.

Wilson, E. K. (2014). Theorizing Religion as Politics in Postsecular International Relations." Politics, Religion \& Ideology, (15)3, 347-365.

Winters, M. (2014). Targeting, Accountability and Capture in Development Projects. International Studies Quarterly, (58)2, 393-404.

Wirdyaningsih. (Ed). (2005). Bank dan Asuransi Islam di Indonesia. Jakarta:Prenada Media. 